\title{
EATING BEHAVIOURS AND ALEXITHYMIC FEATURES OF OBESE AND OVERWEIGHT ADOLESCENTS
}

\author{
zehra boybay $^{1}$ \\ ${ }^{1}$ Affiliation not available
}

June 23, 2021

Eating Behaviour and Alexithymia

Zehra Koyuncu MD*a , Muhammed Tayyib Kadak MD ${ }^{\mathrm{b}}$, Mahmut Cem Tarakçığlu ${ }^{\mathrm{c}}$, Rahime Hülya Bingöl Çağlayan $\mathrm{MD}^{\mathrm{d}}$, Burak Doğangün $\mathrm{MD}^{\mathrm{e}}$, Oya Ercan $\mathrm{MD}^{\mathrm{f}}$

- Medical Doctor, Department of Child and Adolescent Psychiatry, Cerrahpasa Medical Faculty, Istanbul University-C, Istanbul, Turkey,zboybay@gmail.com, ORCID: 000-0001-6458-1826

- Associate Professor, Department of Child and Adolescent Psychiatry, Cerrahpasa Medical Faculty, Istanbul University-C, Istanbul, Turkey, tayyibkadak@gmail.com, ORCID: 0000-0003-0016-311X

- Associate Professor, Department of Child and Adolescent Psychiatry, Cerrahpasa Medical Faculty, Istanbul University-C, Istanbul, Turkey,mtarakcioglu@hotmail.com, ORCID: 0000-0002-0159-1864

- Medical Doctor, Department of Child and Adolescent Psychiatry, Cerrahpasa Medical Faculty, Istanbul University-C, Istanbul, Turkey, rhulyabingol@gmail.com, ORCID: 0000-0002-9414-7147

- Professor Doctor, Department of Child and Adolescent Psychiatry, Cerrahpasa Medical Faculty, Istanbul University-C, Istanbul, Turkey, burakdogangun@hotmail.com, ORCID: 0000-0002-0106-8256

- Professor Doctor, Pediatric Endocrinology and Adolescent Divisions, Istanbul University-C, Cerrahpasa Medical Faculty, Istanbul, Turkey, oyaercan1@gmail.com, ORCID: 0000-0001-7397-2837

*Corresponding author, Zehra Koyuncu,

+905077069280 ,

Istanbul University Cerrahpasa Medical Faculty Campus Kocamustafapasa Street No: 53 Cerrahpasa, 34098 Fatih / ISTANBUL

\section{Abstract}

Background: In this study, eating behaviors and alexithymia levels in obese adolescents are investigated. Relationships between alexithymia, eating behaviour and insulin resistance are studied.

Method: A patient group and a comparison group are formed. The patient group consists of 87 obese adolescents or overweight adolescents $(\mathrm{O}+\mathrm{OW})$. The comparison group consists of 101 normal weight adolescents (N). Alexithymia Questionnaire for Children (AQC), Dutch Eating Behavior Questionnaire (DEBQ) and Revised Child Anxiety and Depression Scale-Child Version (RCADS-CV) are used for assessing adolescents. Homeostasis model assessment-estimated insulin resistance (HOMA-IR) are calculated to determine insuline resistance.

Results: AQC scores are significantly higher in $\mathrm{O}+\mathrm{OW}$ compared to $\mathrm{N}$ (p:0,009) . Both emotional and restrained eating scores are higher in $\mathrm{O}+\mathrm{OW}(\mathrm{p}<0,001$ for both). On the other hand, external eating scores do not have any significant difference. In $\mathrm{O}+\mathrm{OW}$, external eating is positively associated with HOMA-IR (r:035, p:0,006), but is not associated with fasting blood glucose and HbA1c (r:-0,05, p:0,62; r:-0,05, p:0,73). 
Regression analysis shows that restrained and emotional eatings are predictors of $\mathrm{O}+\mathrm{OW}(\mathrm{B}: 0,1, \mathrm{p}<0,001$; $\mathrm{B}: 0,06, \mathrm{p}: 0,001)$. Emotional eating is positively correlated with AQC and RCADS-CV in O+OW (r: 0,29, p: $0,008 ; \mathrm{r}: 0,48, \mathrm{p}<0,001)$

Conclusion: Obese and overweight adolescents are more alexithymic than normal weight adolescents. Also, alexithymia scores are positively associated with emotional eating. On the other hand, alexithymia is not a predictor of obesity/overweight. Restrained and emotional eatings are predictors of obesity/overweight. Emotional and restrained eatings are more common in obese and overweight adolescents compared to normal weighted adolescents. External eating is not significantly associated with obesity, but is related with insuline resistance.

Keyword: obesity, childhood, alexithymia, restrained eating, emotional eating

\section{Introduction}

Childhood obesity and overweight is considered an important public health problem due to its increasing prevalences in many low and middle income countries (1). Many psychiatric factors such as internalizing and externalizing symptoms are found to be associated with childhood obesity (2).

Alexithymia is defined as inability to find words to describe one's own feelings (3). As a way of coping with emotions, several studies suggest that the alexithymic patients might develop negative eating behaviors (4)(5)(6). Although there are many studies showing that alexithymic features are more common in obese individuals (7), studies that show no significant relationship between body mass index (BMI) and alexithymic characteristics are also reported (8)(9). Therefore, the role of alexithymia in the development of obesity is not fully understood (7).

Emotion recognition or regulation problems may increase emotional eating which can be defined as increased amount of eating in negative affective situations such as stress. Therefore this mechanism may also cause obesity (10)(11). People with high alexithymic properties are reported to be more prone to relieve their emotional tension by excessive eating (12).

Insulin resistance, known as impaired function of insulin in balancing plasma and hepatic glucose levels (13), is considered as a risk factor for many health problems such as essential hypertension (14) and Type 2 Diabetes Mellitus (15), and is frequently associated with obesity (16). It is known that insulin resistance can cause increased food consumption and disinhibition of eating (17).

Studies examining the relationship between alexithymia and eating behaviour in obese people have been reported mostly in the adult age group. In children and adolescents, the relationship between alexithymia levels and effect of emotional and external factors on the amount of food consumption is less investigated (18). Also, to our knowledge, there are no studies conducted in Turkish population. Understanding the relationship between emotional eating and alexithymia can be a guide for psychosocial interventions in the treatment process of obese youth. We predict that obese adolescents or overweight adolescents $(\mathrm{O}+\mathrm{OW})$ have more alexithymic features than normal weight adolescents $(\mathrm{N})$. Therefore, $\mathrm{O}+\mathrm{OW}$ are more prone to have problematic eating behaviours. Main objective of this study is to investigate the relationship between alexithymia levels and problematic eating behaviours such as emotional, restrained and external eatings in obese and overweight adolescents. Possible predictors of obesity/overweight among these factors are determined. To reveal effect of insuline resistance on eating behaviour, the association between insulin resistance and emotional, restrained and external eating levels is investigated.

\section{Method}

The data used in this study is obtained from Zehra Koyuncu's doctoral thesis (referanslara ekleyebilirsiniz). Cases with subtreshold depression and anxiety symptoms are used in the analysis.

\section{Participants:}

A hundred and four adolescents (11-16 years old) with a BMI percentile above 85 were recruited from 
Department of Pediatrics, Adolescent Outpatient Clinic Unit, Cerrahpaşa Medical School. The reference values determined by Neyzi et al. (19) for Turkish children were used to determine the percentile of the BMI. Patients with BMI above 95 were considered Obese $(\mathrm{O})$ and those between 85 and 95 were assumed Overweight (OW) (20). Adolescents who had antipsychotic or corticosteroid medicine in the last 6 months, who were diagnosed with mental retardation, autism spectrum disorder and schizophrenia spectrum disorder and who were illiterate were not included. Participants with depression/anxiety scores higher than clinical treshold were excluded from the statistical analysis due to the reported relationship between alexithymia and depression/anxiety disorder (21)(22). Seventeen adolescents were excluded because of using antipsychotic drugs, missing data and having RCADS-CV score above clinical treshold (70). Therefore, statistical analysis was conducted with 87 patients.

Comparison group were recruited from middle and high schools in Istanbul. Adolescents with a BMI percentile between 5 and 85 with similar sociodemographic characteristics were enrolled in as the comparison group. The objective of the study and the tests were explained to the adolescents and their parents. Those who accepted were included in the study. One hundred and fifty two adolescents were tested for the purpose of creating the comparison group. 51 members of the tested adolescents were removed because of missing forms $(n=25)$, inappropriate BMI $(n=16)$, being diagnosed with a psychiatric disorder during the study $(\mathrm{n}=1)$, having RCADS-CV t score above the clinical treshold $(\mathrm{n}=9)$. As a result, the comparison group was formed with 101 adolescents. Permissions were obtained from relevant educational institutions and written consent was obtained from each participants and their parents. The participants were asked to fill in surveys which lasted about 30 minutes. In addition, HOMA-IR value, which is a reliable method to evaluate insulin resistance, was calculated in obese adolescents. The formula for the HOMA-IR value is $\frac{\text { fasting insulin concentration } x \text { fasting glucose concentration }}{22.5}(23)$.

The Declaration of Helsinki was used as the standard of medical ethics in the study design. The Istanbul University-Cerrahpasa, Cerrahpasa Medical School Ethics Committee reviewed and approved all study materials (83045809-604.01.02-).

\section{Instruments:}

The Sociodemographic Data Form was created by researchers to record information on age, gender, number of siblings, number of children, presence of chronic diseases, psychiatric disease history, weight and height, family income, family integrity, parental loss, age, educational level and occupation of parents.

Alexithymia Questionnaire for Children (AQC) was developed by Rieffe et al.(24) to measure children's alexithymia levels. The scale consists of 20 items (24). Koçak et al. (25) adapted this scale to Turkish and conducted a reliability study. Reliability coefficient values was very close to the original scale. The Cronbach alpha internal consistency coefficient of the scale was .78. Higher total score from the scale indicates more alexithymic properties (24).

The Dutch Eating Behavior Questionnaire (DEBQ) was developed in 1986 by Van Strien et al. (26). The DEBQ is used to identify external stimuli and internal stimuli other than fasting, that affect eating behavior. In addition to the 'Restrained Eating' scale which assesses food intake restriction, a new questionnaire was developed by adding the 'Emotional Eating' scale and the 'External Eating' scale which asseses eating in response to food-related stimuli (26). The questionnaire was adapted to Turkish and the validity and reliability study was performed by Bozan (27). The internal consistency coefficient of the whole scale was found to be .94 (27).

Revised Child Anxiety and Depression Scale- Child Version (RCADS-CV) was developed in 2000 by Chorpita et al. (29) based on the Spence Children's Anxiety Scale (28). The Turkish validity study was carried out by Gormez et al.(30). Cronbach alfa value was calculated as 95 (30). A T score of 70 was reported as clinical treshold (31).

\section{Statistical Analysis}

All data were analyzed using SPSS software package 22.0. Mean, standard deviation, median, lowest, highest, 
frequency and ratio values were used in descriptive statistics of the data. The distribution of variables was measured by the Shapiro Wilk test. In the analysis of quantitative independent data, Student $t$ test and Mann-Whitney test were used. Chi-square test was used for the analysis of qualitative independent data and fischer test was used when the chi-square test conditions were not satisfied. Spearman correlation analysis was used in the correlation analysis. Lastly, potential predictors of obesity and overweight were determined by Multiple Linear Regression Analysis. Statistically, values of $\mathrm{p}<0.05$ were considered significant.

\section{Results}

\subsection{Comparison of Obese+Overweight with Normal}

The mean age of the $\mathrm{O}+\mathrm{OW}$ was $13.5 \pm 1.2$ years and the mean age of the control group was $13.6 \pm 1.3$ year $(\mathrm{p}>0.05)$. When $\mathrm{O}+\mathrm{OW}$ were compared with $\mathrm{N}$, weight and BMI were significantly higher in $\mathrm{O}+\mathrm{OW}(\mathrm{p}<$ $0,001)$. There was no significant difference $(\mathrm{p}>0.05)$ between the height, parental education, family income and integrity between $\mathrm{N}$ and $\mathrm{O}+\mathrm{OW}$ (Table 1). AQC scores were significantly higher in $\mathrm{O}+\mathrm{OW}$ than $\mathrm{N}$ (p:0.009). The DEBQrestrained eating and emotional eating subscale scores of $\mathrm{O}+\mathrm{OW}$ were significantly higher than the scores of $\mathrm{N}(\mathrm{p}<0,001$ for both). The DEBQ external eating subscale score did not differ significantly between $\mathrm{O}+\mathrm{OW}$ and $\mathrm{N}(\mathrm{p}>0.05)$. (Table 2).

\subsection{Correlational analysis}

In $\mathrm{O}+\mathrm{OW}$, emotional eating was weakly and positively correlated with AQC (r: 0,29, p: 0,008). It is moderately and positively correlated with RCADS total scores ( $\mathrm{r}: 0,48, \mathrm{p}<0,001)$. The relationship between eating behaviour and HOMA-IR shows that there is a weak and positive correlation between DEBQ external eating score and HOMA-IR value in the obese participants (r:035, p:0,006). External eating was not associated with fasting blood glucose and HbA1c (r:-0,05, p:0,62; r:-0,05, p:0,73).

\section{(Table 3)}

\subsection{Regression Analysis}

Multiple Linear Regression Analysis was performed to evaluate potential determinants of being obese/overweight. Being obese/overweight was the dependent variable, restrained eating, emotional eating, AQC and RCADS-CV total scores were independent variables. Of these factors, restrained and emotional eating were obtained as predictors of being obese/overweight (B:0,1, p: $<0.001 ; \mathrm{B}: 0,06, \mathrm{p}:<0,001)$. (Table 4)

\section{Discussion}

This study investigated the association between alexithymia and eating behaviours like emotional, restrained, external eating in $\mathrm{O}$, OW and $\mathrm{N}$. While alexithymic properties, restrained eating and emotional eating behaviour were significantly different between groups, external eating attitude was similar. Alexithymia was weakly and positively correlated with emotional eating, but no correlation was observed with restrained or external eating. External eating was positively correlated with HOMA-IR. Sociodemografic characteristics that may cause psychological symptoms were similar between the groups except for sibling number and chronic disease history.

\section{Alexithymia and Obesity/Overweight}

In agreement with previous studies (18)(32), our results showed that adolescents with obesity or overweight were more alexithymic. Obese/overweight adolescents who are more alexithymic had more emotional eating which was prominent in obese and overweight adolescents. These results was consistent with psychosomatic theory (1). The positive association between alexithymia and emotional eating shows that identification and verbalization of emotions may help to reduce acting outs such as overeating. Although alexithymia levels higher in obese and overweight adolescents, in regression analysis it was shown that alexithymia is not a predictor of obesity or overweight. Because the potential prediction relationship was not examined in previous studies, this result is a unique contribution to the literature. Furthermore, unlike previous studies in the literature (18)(32), in our study, depression/anxiety scores was evaluated and participants with clinical level 
symptoms of depression/anxiety were excluded. Therefore, the results are more specific to obesity/overweight. It can be concluded that our findings support the existence and importance of emotional and psychological factors of obesity.

\section{Alexithymia and Eating Behaviour}

While alexithymia is a problem in describing and expressing emotions, emotional eating refers to a problematic response to emotions. There is a weak and positive association between alexithymia andemotional eating which is a predictor of obesity/overweight according to our study. This result confirms our hypothesis which claim that alexithymia and emotional eating are related conditions. Adolescents who are more alexithymic may be more prone to cope with emotions by acting-outs such as overeating. According to our study and previous reports based on general adolescent population (5)(6), alexithymia can be considered a managable risk factor for disruptive eating behaviour and excess weight. Moreover investigation of effect of recognizing and expressing emotions on disordered eating and BMI in further studies, may be a guide in obesity/overweight management. In other words, excess weight and disruptive eating behaviours can be considered as physical and action based expressions of emotional properties and problems. Additionally, similar to the coping mechanism based on overeating, obese adolescents may have other maladaptive mechanisms for coping with emotions. This topic may be a future research direction in this area.

\section{Predictors for Being Obese/Overweight}

Regression analysis shows that both restrained and emotional eating are predictors of obesity/overweight and restrained eating is a stronger predictor compared to emotional eating. As a result, restrained eating is a more important factor than emotional eating for high BMI. However, it must be considered that evaluation of restrained eating in our study are based on self reports. Therefore, although participants' responses provide information about their efforts for eating less, there is no quantitative information about real calorie intakes. Unlike long fasting periods and overeating attacks in bulimia nervosa (37), in obese people, calorie restriction may be only on cognitive level. Restrained eating pattern could only be a diet attempt caused by stress factors associated with having a high BMI. On the other hand, considering positive correlation between emotional eating and depression/anxiety scores, emotional eating can be regarded as a more maladaptive behaviour compared to restrained eating in obesity.

\section{Insulin Resistance and Eating Behaviour}

While emotional eating is related with psychological factors like depression/anxiety symptoms or alexithymia, external eating is positively but weakly correlated with HOMA-IR. However, there were no associations between fasting blood glucose and external eating. These findings suggest that, in obese and overweight adolescents, external eating may not be a response to low blood glucose levels. Also, it can be recommended to evaluate insuline levels in obese/overweight adolescents who are reactive to the food related clues.

\section{Strenghts and Limitations}

There are two limitations in this study. Clinical evaluations by an experienced clinician could provide more valid information to evaluate alexithymic features. Also, due to the cross-sectional design of the study, we could not obtain results regarding the causality.

This study has also some strengths. One of them was larger sample size compared to similar studies in the literature. In addition, considering the psychiatric symptoms and factors affecting alexithymia helped us to better understand the relationship between alexithymia and obesity. Finally, the predictors of obesity/overweight were examined by regression analysis.

As a conclusion, obese and overweight adolescents have more alexithymic properties. These properties have positive associations with overeating which is triggered by emotional states. But alexithymia is not a predictor of obesity/overweight. It is shown that problematic eating behaviors such as restrained and emotional eatings are predictors of obesity/overweight. While emotional and restrained eatings were more common in obese and overweight adolescents, responding with overeating to food related cues was not significantly associated 
with obesity, but was related with insuline resistance in obese adolescents. Additionally, emotional eating was found to be positively associated with alexithymia and depression / anxiety symptoms and it is concluded that emotional eating is related with psychological factors.

\section{References}

1. WHO. Childhood overweight and obesity [Internet]. [cited 2020 Oct 1]. Available from:https://www.who.int/dietphysicalactivity/childhood/en/

2. Rankin J, Matthews L, Cobley S, Han A, Sanders R, Wiltshire HD, et al. Psychological consequences of childhood obesity: psychiatric comorbidity and prevention. Adolesc Health Med Ther. 2016;7:125.

3. Sifneos PE. Alexithymia and its relationship to hemispheric specialization, affect, and creativity. Psychiatr Clin. 1988;11(3):287-92.

4. Cooper MJ. Cognitive theory in anorexia nervosa and bulimia nervosa: Progress, development and future directions. Clin Psychol Rev. 2005;25(4):511-31.

5. Alpaslan AH, Soylu N, Kadriye A, Coşkun KŞ, Kocak U, Taş HU. Disordered eating attitudes, alexithymia and suicide probability among Turkish high school girls. Psychiatry Res. 2015;226(1):224-9.

6. Shank LM, Tanofsky-Kraff M, Kelly NR, Jaramillo M, Rubin SG, Altman DR, et al. The association between alexithymia and eating behavior in children and adolescents. Appetite. 2019;142:104381.

7. Fernandes J, Ferreira-Santos F, Miller K, Torres S. Emotional processing in obesity: a systematic review and exploratory meta-analysis. Obes Rev. 2018;19(1):111-20.

8. de Zwaan M, Bach M, Mitchell JE, Ackard D, Specker SM, Pyle RL, et al. Alexithymia, obesity, and binge eating disorder. Int J Eat Disord. 1995;17(2):135-40.

9. Karagöl A, Özçürümez G, Taşkıntuna N, Nar A. Beden kitle indeksinin depresyon ve aleksitimi ile ilişkisi. Anatol J Psychiatry/Anadolu Psikiyatr Derg. 2014;15(3).

10. Wegener I, Wawrzyniak A, Imbierowicz K, Conrad R, Musch J, Geiser F, et al. Evidence for attenuated affective processing in obesity. Psychol Rep. 2008;103(1):35-47.

11. Vandewalle J, Moens E, Braet C. Comprehending emotional eating in obese youngsters: the role of parental rejection and emotion regulation. Int J Obes. 2014;38(4):525.

12. Legorreta G, Bull RH, Kiely MC. Alexithymia and symbolic function in the obese. Psychother Psychosom. 1988;50(2):88-94.

13. Ten S, Maclaren N. Insulin resistance syndrome in children. J Clin Endocrinol Metab. 2004;89(6):252639.

14. Ferrannini E, Buzzigoli G, Bonadonna R, Giorico MA, Oleggini M, Graziadei L, et al. Insulin resistance in essential hypertension. N Engl J Med. 1987;317(6):350-7.

15. Martin BC, Warram JH, Krolewski AS, Soeldner JS, Kahn CR, Bergman RN. Role of glucose and insulin resistance in development of type 2 diabetes mellitus: results of a 25-year follow-up study. Lancet. 1992;340(8825):925-9.

16. Thota P, Perez-Lopez FR, Benítes-Zapata VA, Pasupuleti V, Hernandez A V. Obesity-related insulin resistance in adolescents: a systematic review and meta-analysis of observational studies. Gynecol Endocrinol. 2017;33(3):179-84.

17. Singh MK, Leslie SM, Packer MM, Zaiko Y V, Phillips OR, Weisman EF, et al. Brain and behavioral correlates of insulin resistance in youth with depression and obesity. Horm Behav. 2019;108:73-83. 
18. Casagrande M, Boncompagni I, Forte G, Guarino A, Favieri F. Emotion and overeating behavior: effects of alexithymia and emotional regulation on overweight and obesity. Eat Weight Disord Anorexia, Bulim Obes. 2020;25(5):1333-45.

19. Neyzi O, Günöz H, Furman A, Bundak R, Gökçay G, Darendeliler F. Türk çocuklarında vücut ağırlığı, boy uzunluğu, baş çevresi ve vücut kitle indeksi referans değerleri. Çocuk Sağlı̆̆ı ve Hast Derg. 2008;51(1):114.

20. Defining Childhood Obesity | Overweight \& Obesity | CDC [Internet]. [cited 2019 Nov 1]. Available from:https://www.cdc.gov/obesity/childhood/defining.html\#targetText=Obesityis defined as a,as BMIfor-age.

21. Da Ros A, Vinai P, Gentile N, Forza G, Cardetti S. Evaluation of alexithymia and depression in severe obese patients not affected by eating disorders. Eat Weight Disord Anorexia, Bulim Obes. 2011;16(1):24-9.

22. Eizaguirre AE, de Cabezón AOS, de Alda IO, Olariaga LJ, Juaniz M. Alexithymia and its relationships with anxiety and depression in eating disorders. Pers Individ Dif. 2004;36(2):321-31.

23. Keskin M, Kurtoglu S, Kendirci M, Atabek ME, Yazici C. Homeostasis model assessment is more reliable than the fasting glucose/insulin ratio and quantitative insulin sensitivity check index for assessing insulin resistance among obese children and adolescents. Pediatrics. 2005;115(4):e500-3.

24. Rieffe C, Oosterveld P, Terwogt MM. An alexithymia questionnaire for children: Factorial and concurrent validation results. Pers Individ Dif. 2006;40(1):123-33.

25. Koçak R, Karaboğa M, Baloğlu M. Çocuklar İçin Aleksitimi Ölçeği (Çaö) Türkçe'ye Uyarlanması: Geçerlik Ve Güvenirlik Çalı̧̧ması. Electron Turkish Stud. 2015;10(11).

26. Van Strien T, Frijters JER, Bergers GPA, Defares PB. The Dutch Eating Behavior Questionnaire (DEBQ) for assessment of restrained, emotional, and external eating behavior. Int J Eat Disord. $1986 ; 5(2): 295-315$.

27. Bozan N, Bas M, Asci FH. Psychometric properties of Turkish version of Dutch Eating Behaviour Questionnaire (DEBQ). A preliminary results. Appetite. 2011;56(3):564-6.

28. Spence SH. A measure of anxiety symptoms among children. Behav Res Ther. 1998;36(5):545-66.

29. Chorpita BF, Yim L, Moffitt C, Umemoto LA, Francis SE. Assessment of symptoms of DSM-IV anxiety and depression in children: A revised child anxiety and depression scale. Behav Res Ther. 2000;38(8):835-55.

30. Gormez V, Kılınçaslan A, Orengul AC, Ebesutani C, Kaya I, Ceri V, et al. Psychometric properties of the Turkish version of the Revised Child Anxiety and Depression Scale-Child Version in a clinical sample. Psychiatry Clin Psychopharmacol. 2017;27(1):84-92.

31. Chorpita BF, Ebesutani C, Spence SH. Revised Children's Anxiety and Depression Scale User's Guide [Internet]. 2015 [cited 2021 Feb 2]. p. 4. Available from:https://www.childfirst.ucla.edu/wpcontent/uploads/sites/163/2018/03/RCADSUsersGuide20150701.pdf

32. Surcinelli P, Baldaro B, Balsamo A, Bolzani R, Gennari M, Rossi NCF. Emotion recognition and expression in young obese participants: preliminary study. Percept Mot Skills. 2007;105(2):477-82.

33. van Strien T. Eating behaviour, personality traits and body mass. Van Strien; 1986.

34. Wardle J, Marsland L, Sheikh Y, Quinn M, Fedoroff I, Ogden J. Eating style and eating behaviour in adolescents. Appetite. 1992;18(3):167-83.

35. Snoek HM, Engels RCME, Van Strien T, Otten R. Emotional, external and restrained eating behaviour and BMI trajectories in adolescence. Appetite. 2013;67:81-7. 
36. Cools J, Schotte DE, McNally RJ. Emotional arousal and overeating in restrained eaters. J Abnorm Psychol. 1992;101(2):348.

37. Wade TD. Recent research on bulimia nervosa. Psychiatr Clin. 2019;42(1):21-32.

38. Harrist AW, Hubbs-Tait L, Topham GL, Shriver LH, Page MC. Emotion regulation is related to children's emotional and external eating. J Dev Behav Pediatr. 2013;34(8):557-65.

39. Burton P, Smit HJ, Lightowler HJ. The influence of restrained and external eating patterns on overeating. Appetite. 2007;49(1):191-7.

40. Van Strien T, Herman CP, Verheijden MW. Eating style, overeating, and overweight in a representative Dutch sample. Does external eating play a role? Appetite. 2009;52(2):380-7.

41. Sung J, Lee K, Song Y-M. Relationship of eating behavior to long-term weight change and body mass index: the Healthy Twin study. Eat Weight Disord Anorexia, Bulim Obes. 2009;14(2-3):e98-105.

\begin{tabular}{|c|c|c|}
\hline TABLE-1 & TABLE-1 & TABLE-1 \\
\hline Gender & Gender & $\begin{array}{l}\text { Boy } \\
\text { Girl }\end{array}$ \\
\hline Age & Age & Age \\
\hline Weight (kg) & Weight (kg) & Weight (kg) \\
\hline Height (cm) & Height $(\mathrm{cm})$ & Height $(\mathrm{cm})$ \\
\hline BMI & BMI & $\mathrm{BMI}$ \\
\hline Mother Age & Mother Age & Mother Age \\
\hline Father Age & Father Age & Father Age \\
\hline Sibling Number & Sibling Number & Sibling Number \\
\hline Psychiatric referral history & Psychiatric referral history & Psychiatric referral history \\
\hline Chronic disease history & Chronic disease history & Chronic disease history \\
\hline High school and higher education of mother & High school and higher education of mother & High school and higher educat \\
\hline High school and higher education of mother & High school and higher education of mother & High school and higher educat \\
\hline Family income & $4500 \mathrm{TL}>$ per month & $4500 \mathrm{TL}>$ per month \\
\hline \multirow[t]{3}{*}{ Family Integrity } & Married & Married \\
\hline & Divorced & Divorced \\
\hline & Other & Other \\
\hline
\end{tabular}

m Mann-whitney u test $/ \mathrm{x}^{2}$ Chi-Square test Standard deviation $\mathrm{O}+\mathrm{OW}$ : Obese and overweight N: Normal weight BMI: Body Mass Index

\begin{tabular}{|c|c|c|c|c|c|}
\hline TABLE-2 & $\mathrm{O}+\mathrm{OW}(87)$ & $\mathrm{O}+\mathrm{OW}(87)$ & $\mathrm{N}(101)$ & $\mathrm{N}(101)$ & $\mathrm{p}$ \\
\hline $\mathrm{AQC}$ & $\begin{array}{l}\text { Mean.土s.d. } \\
15,8\end{array}$ & $\begin{array}{l}\text { Mean.土s.d. } \\
\pm 4,4\end{array}$ & $\begin{array}{l}\text { Mean.土s.d. } \\
14,2\end{array}$ & $\begin{array}{l}\text { Mean.土s.d. } \\
\pm 4,2\end{array}$ & $0,009 \mathrm{t}$ \\
\hline DEBQ-Restrained & 26,0 & $\pm 8,3$ & 19,6 & $\pm 8,6$ & $<0,001 \mathrm{t}$ \\
\hline DEBQ-Emotional & 27,0 & $\pm 14,2$ & 18,4 & $\pm 10,1$ & $<0,001 \mathrm{~m}$ \\
\hline DEBQ-External & 27,0 & $\pm 9,3$ & 26,1 & $\pm 7,6$ & $0,611 \mathrm{t}$ \\
\hline RCADS Total & 40,3 & $\pm 17,0$ & 34,4 & $\pm 13,5$ & $0,015 \mathrm{t}$ \\
\hline
\end{tabular}

m Mann-whitney u test, ${ }^{\mathrm{t}}$ Student $\mathrm{t}$ test s.d. Standard deviation $\mathrm{O}+\mathrm{OW}$ : Obese and overweight N: Normal weight DEBQ: Dutch Eating Behaviour Questionaire AQC : Alexithymia Questionnaire for Children 


\begin{tabular}{llllllll}
\hline TABLE 3 & TABLE 3 & FBG & HbA1c & HOMA-IR & DEBQ-Restrained & DEBQ-Emotional & DEBQ-External \\
\hline DEBQ-Restrained & $\mathrm{r}$ & 0,06 & 0,03 & 0,06 & 1,0 & 0,03 & $-0,19$ \\
& $\mathrm{p}$ & 0,58 & 0,81 & 0,63 & & 0,79 & 0,08 \\
DEBQ-Emotional & $\mathrm{r}$ & $-0,17$ & 0,07 & 0,23 & 0,03 & 1,0 & $\mathbf{0 , 2 2}$ \\
& $\mathrm{p}$ & 0,14 & 0,63 & 0,08 & 0,79 & & $\mathbf{0 , 0 4}$ \\
DEBQ-External & $\mathrm{r}$ & $-0,05$ & $-0,05$ & $\mathbf{0 , 3 5}$ & $-0,19$ & $\mathbf{0 , 2 2 9}$ & 1,0 \\
& $\mathrm{p}$ & 0,62 & 0,73 & $\mathbf{0 , 0 0 6}$ & 0,08 & $\mathbf{0 , 0 4}$ & \\
\hline
\end{tabular}

Spearman Correlation in O+OW, DEBQ: Dutch Eating Behaviour Questionaire FBG: Fasting Blood Glucose RCADS: Revised Child Anxiety and Depression Scale-Child Version AQC : Alexithymia Questionnaire for Children

TABLE 4

\begin{tabular}{llll}
\hline Dependent Variable: Group $(\mathrm{O}+\mathrm{OW} / \mathrm{N})$ & $\mathrm{B}$ & $\mathrm{p}$ & $95 \% \mathrm{CI}$ Lower/Upper \\
\hline Restrained & $\mathbf{0 , 1 0}$ & $<\mathbf{0 , 0 0 1}$ & $\mathbf{1 , 0 5} / \mathbf{1 , 1 6}$ \\
Emotional & $\mathbf{0 , 0 6}$ & $\mathbf{0 , 0 0 1}$ & $\mathbf{1 , 0 2} / \mathbf{1 , 1 0}$ \\
AQC & 0,07 & 0,63 & $0,97 / 1,03$ \\
RCADS-CV & 0,00 & 0,15 & $0,97 / 1,18$ \\
\hline
\end{tabular}

Multiple Linear Regression Analysis $\mathrm{O}+\mathrm{OW}$ : Obese and Overweight, $\mathrm{N}$ : Normal weight, $\mathrm{O}+\mathrm{OW} / \mathrm{N}$ : Being O / OW or N, RCADS: Revised Child Anxiety and Depression Scale-Child Version AQC : Alexithymia Questionnaire for Children CI: Confidence Interval 